\title{
Short- and long-term effects of biliary drainage on hepatic cholesterol metabolism in the rat
}

\author{
Martin J. SMIT, Arno M. TEMMERMAN, Rick HAVINGA, Folkert KUIPERS and Roel J. VONK \\ Department of Pediatrics, University of Groningen, Bloemsingel 10, $9712 \mathrm{KZ}$ Groningen, The Netherlands
}

\begin{abstract}
The present study concerns short- and long-term effects of interruption of the enterohepatic circulation (EHC) on hepatic cholesterol metabolism and biliary secretion in rats. For this purpose, we employed a technique that allows reversible interruption of the EHC, during normal feeding conditions, and excludes effects of anaesthesia and surgical trauma. $\left[{ }^{3} \mathrm{H}\right]$ Cholesteryl oleate-labelled human low-density lipoprotein (LDL) was injected intravenously in rats with (1) chronically (8 days) interrupted EHC, (2) interrupted EHC at the time of LDL injection and (3) intact EHC. During the first $3 \mathrm{~h}$ after interruption of the EHC, bile flow decreased to $50 \%$ and biliary bile acid, phospholipid and cholesterol secretion to $5 \%, 11 \%$ and $19 \%$ of their initial values respectively. After 8 days of bile diversion, biliary cholesterol output and bile flow were at that same level, but bile acid output was increased 2-3-fold and phospholipid output was about 2 times lower. The total amount of cholesterol in the liver decreased after interruption of the EHC, which was mainly due to a decrease in the amount of cholesteryl ester. Plasma disappearance of LDL was not affected by interruption of the EHC. Biliary secretion of LDL-derived radioactivity occurred 2-4 times faster in chronically interrupted rats as compared with the excretion immediately after interruption of the EHC. Radioactivity was mainly in the form of bile acids under both conditions. This study demonstrates the very rapid changes that occur in cholesterol metabolism and biliary lipid composition after interruption of the EHC. These changes must be taken into account in studies concerning hepatic metabolism of lipoprotein cholesterol and subsequent secretion into bile.
\end{abstract}

\section{INTRODUCTION}

The hepatobiliary pathway is the main route for removal of cholesterol from the body [1,2], yet little information is available on the coupling of hepatic lipoprotein uptake to subsequent biliary secretion of its cholesterol content. The commonly used methods for bile collection in experimental animals are carried out under anaesthesia or stress of restraint $[3,4]$, i.e. factors known to interfere with sterol synthesis, splanchnic blood flow and intestinal motility [5-7]. A number of techniques have been described to exclude these unwanted side effects [8-10]. In our laboratory, we have developed a technique in which rats are equipped with permanent catheters in the bile duct, duodenum and heart [10]. This technique allows interruption and subsequent restoration of the enterohepatic circulation (EHC), as well as frequent blood sampling and/or intravenous injection of compounds in unanaesthetized unrestrained animals, with a normal feeding pattern.

Experiments carried out in the period immediately after interruption of the EHC, i.e. during depletion of the bile acid pool, are difficult to interpret because of the continuously changing system. This problem can be circumvented by using rats with a chronically interrupted $\mathrm{EHC}$ in which a new steady state has been established [10]. However, this new steady state differs from the intact situation in a number of aspects; to evaluate this methodological problem, we have studied shortand long-term changes that occur in hepatic cholesterol metabolism in our rat model. Changes in the total amount of cholesterol, bile acid synthesis and the activity of the ratelimiting enzymes in cholesterol synthesis, cholesterol esterification and bile acid synthesis in the liver were monitored. In addition, intravenously administered $\left[{ }^{3} \mathrm{H}\right]$ cholesteryl oleatelabelled human low-density lipoprotein (LDL) was used as a tool to monitor changes in the hepatic processing and bile secretion of lipoprotein-derived cholesterol.

\section{MATERIALS AND METHODS}

\section{Materials}

Tween-80, Triton WR-1339, glucose 6-phosphate, fatty acidfree BSA, oleoyl-CoA, 3-hydroxy-3-methylglutaryl-CoA (HMG$\mathrm{CoA})$ and mevalonic acid lactone were purchased from Sigma Chemical Co., St. Louis, MO. U.S.A. Glucose-6-phosphate dehydrogenase, dithiothreitol, NADP ${ }^{+}$and ATP were from Boehringer, Mannheim, Germany. Cholesterol, $7 \alpha$ hydroxycholesterol and $7 \beta$-hydroxycholesterol were from Steraloids, Wilton, NH, U.S.A. 3-Hydroxy-3-methyl$\left[3-{ }^{14} \mathrm{C}\right]$ glutaryl-CoA and $\left[4-{ }^{14} \mathrm{C}\right]$ cholesterol were from The Radiochemical Centre, Amersham, Bucks., U.K. [5$\left.{ }^{3} \mathrm{H}\right] \mathrm{Mevalonic}$ acid lactone and $\left[1-{ }^{14} \mathrm{C}\right]$ oleoyl-CoA were obtained from New England Nuclear Corp., Boston, MA, U.S.A. All other chemicals used were of analytical grade.

\begin{abstract}
Animals
Male Wistar rats (250-325 g) were housed individually in Plexiglass cages in a temperature- and light-controlled room (temperature $20^{\circ} \mathrm{C}$; lights on 06:00-18:00 h). Water and pellet food were available ad libitum. The pellet food (type RMH-B; Hope Farms, Woerden, The Netherlands) contained, per $100 \mathrm{~g}$ of pellets, $24 \mathrm{~g}$ of protein, $6 \mathrm{~g}$ of fat, $4 \mathrm{~g}$ of fibre, $59 \mathrm{~g}$ of carbohydrates and $6 \mathrm{~g}$ of minerals. Three groups of rats were equipped with permanent silicone catheters as described previously [10]. One group was equipped with catheters in bile duct, duodenum and heart, a second group with catheters in bile duct and heart, and a third group with a heart catheter only. These catheters were tunnelled subcutaneously and fixed to the skull. In the first group the EHC was restored immediately after the operation by connection of the bile-duct and duodenal catheters. In the second group the EHC was interrupted continuously. During bile diversion, bile was led through polyethylene tubing
\end{abstract}

Abbreviations used: EHC, enterohepatic circulation; LDL, low-density lipoprotein; HMG, 3-hydroxy-3-methylglutaryl; ACAT, acylCoA:cholesterol acyltransferase. 
with a swivel joint, thus permitting free movement of the rats and allowing bile formation to be studied in conscious and unrestrained animals. The heart catheter allows intracardial administration as well as repeated blood sampling without additional stress to the animals [11]. Animals of all groups rapidly recovered from surgery and reached pre-operation body weights within 3-4 days. Experiments were started after a recovery period of 8 days.

\section{Isolation and labelling of LDL}

Human LDL was isolated from blood of healthy volunteers as described by Redgrave et al. [12] and labelled with [1,2${ }^{3} \mathrm{H}$ ]cholesteryl oleate $(48 \mathrm{Ci} / \mathrm{mmol}$; The Radiochemical Centre) as described by Blomhoff et al. [13], exactly as specified previously [14].

\section{Experimental procedures}

Experiments were performed at 8 days after surgery, i.e. after establishment of a new steady state in cholesterol and bile acid synthesis in the group of rats with permanent biliary drainage [10]. $\left[{ }^{3} \mathrm{H}\right]$ Cholesteryl oleate-labelled human LDL $\left(8 \times 10^{5}\right.$ d.p.m., $50 \mu \mathrm{g}$ of protein) was injected via the heart catheter in all three groups of rats between 11:00 and 11:15 h. At the same time the EHC of the group with the artificially restored circulation was interrupted, and bile of groups 1 and 2 was collected continuously for $22 \mathrm{~h}$ in tared test tubes by using a fraction collector. Blood samples were taken at different time intervals after LDL injection. After $22 \mathrm{~h}$, livers were perfused, excised and assayed for radioactivity, cholesterol, cholesteryl ester and protein.

\section{Preparation of microsomes and assay of $\mathrm{HMG}-\mathrm{CoA}$ reductase, ACAT and cholesterol $7 \propto$-hydroxylase activities}

For the isolation of microsomes a separate set of rats was used. The animals were anaesthetized with diethyl ether, and livers were perfused in situ with ice-cold $0.25 \mathrm{M}$-sucrose until they became yellowish. Livers were immediately excised, cut into small pieces by scissors and divided into three portions, which were homogenized in three different buffers (see below). All procedures were carried out at $4^{\circ} \mathrm{C}$. After centrifugation at $12000 \mathrm{~g}$ for $20 \mathrm{~min}$, microsomes were isolated by centrifugation of the supernatant at $105000 \mathrm{~g}$ for $60 \mathrm{~min}$. The microsomes were resuspended and washed by another centrifugation step at $105000 \mathrm{~g}$ for $60 \mathrm{~min}$. The microsomes were resuspended again (10-25 $\mathrm{mg}$ of microsomal protein $/ \mathrm{ml}$ ), frozen in liquid $\mathrm{N}_{2}$ in small portions, and stored at $-60^{\circ} \mathrm{C}$ under $\mathrm{N}_{2}$.

For the assay of ACAT, the microsomes were isolated in a buffer containing $100 \mathrm{~mm}$-potassium phosphate, $\mathrm{pH} 7.4,1.0 \mathrm{~mm}$ GSH and $10 \mathrm{~mm}$-nicotinamide. For assay of cholesterol $7 \alpha$ hydroxylase, microsomes were isolated in $40 \mathrm{~mm}$-potassium phosphate buffer, $\mathrm{pH} 7.4$, containing $100 \mathrm{~mm}$-sucrose, $50 \mathrm{~mm}$ $\mathrm{KF}, 2.0 \mathrm{~mm}$-EDTA and $5.0 \mathrm{~mm}$-dithiothreitol. After the first $105000 \mathrm{~g}$ ultracentrifugation step, the pellet was resuspended and subsequently washed and stored as described above in the same buffer without KF and with $100 \mathrm{~mm}$-potassium phosphate, $\mathrm{pH}$ 7.4. For the assay of HMG-CoA reductase, microsomes were isolated in a buffer containing $10 \mathrm{~mm}$-potassium phosphate, pH 6.8, $2.0 \mathrm{~mm}$-EDTA and $250 \mathrm{~mm}$-sucrose. After the first $105000 \mathrm{~g}$ ultracentrifugation step, the pellet was resuspended and subsequently washed and stored as described above in a buffer containing $50 \mathrm{~mm}$-Pipes, pH 6.5, $10 \mathrm{~mm}$-EDTA and $100 \mathrm{~mm}$ $\mathrm{NaCl}$.

ACAT activity was determined by measuring the incorporation of $\left[{ }^{14} \mathrm{C}\right]$ oleoyl-CoA into cholesterol as described by Billheimer $e t$ al. [15]. Cholesterol $7 \alpha$-hydroxylase activity was determined by measuring the synthesis of $7 \alpha$-hydroxycholesterol from $\left[{ }^{14} \mathrm{C}\right]$ cholesterol as described by Princen et al. $[16,17]$. HMG-CoA reductase was determined by measuring the conversion of $\left[{ }^{14} \mathrm{C}\right] \mathrm{HMG}-\mathrm{Co} \mathrm{A}$ into mevalonic acid as described by Philipp \& Shapiro [18].

\section{Analysis}

Biliary bile acid concentration was determined by an enzymic fluorimetric assay (Sterognost-Flu; Nyegaard \& Co., Oslo, Norway). Cholesterol and phospholipids in bile were measured after lipid extraction [19], by the methods of Gamble et al. [20] and Böttcher et al. [21] respectively. The masses of cholesterol and cholesteryl ester in liver were determined after lipid extraction [19], by a method using cholesterol oxidase, cholesterol esterase and peroxidase (CHOD-PAP kit; Boehringer Mannheim, catalogue no. 310328). Protein was determined as described by Lowry et al. [22], with BSA as standard.

For measurement of radioactivity, bile and liver homogenate samples were decolorized with an equal volume of $30 \%(\mathrm{v} / \mathrm{v})$ $\mathrm{H}_{2} \mathrm{O}_{2}$, before addition of the scintillant (Hydroluma; J. T. Baker, Deventer, The Netherlands). Plasma samples were counted for radioactivity after addition of Plasmasol (Packard Instrument Co., Downers Grove, IL, U.S.A.). Radioactivity was determined in a LKB liquid-scintillation counter, equipped with an external standard to correct for quenching.

\section{Calculations and statistics}

Output rates of biliary constituents and radioactivity were determined by multiplying bile flow by bile concentrations, after correction of the latter for the dead space of the extracorporeal tubing systems. Values are presented as means \pm S.E.M. Significance of difference was assessed by Student's $t$ test, at a $P<0.05$ level of significance.

\section{RESULTS}

\section{Bile flow and composition}

Bile was collected at $1 \mathrm{~h}$ intervals from a group of rats immediately after interruption of the EHC and from a group of rats which had been bile-diverted for 8 days. Bile flow and output of bile acids, phospholipids and cholesterol during the first $22 \mathrm{~h}$ after interruption of the EHC and at the same time interval at 8 days after interruption are shown in Fig. 1. During the initial $3 \mathrm{~h}$ after interruption of the EHC, bile flow fell to $50 \%$ of its initial value (Fig. 1 $a$ ). During this period, the bile acid pool became exhausted and bile acid output fell from 230 to $12 \mu \mathrm{mol} / \mathrm{h}$ per $\mathrm{kg}$ body wt., i.e. to $5 \%$ of its initial value. Phospholipid and cholesterol outputs decreased to 9.0 and $0.53 \mu \mathrm{mol} / \mathrm{h}$ per $\mathrm{kg}$, i.e. $11 \%$ and $19 \%$ of their initial values respectively. After reaching these low values, output rates of the biliary constituents showed a nocturnal rise, which was more pronounced for cholesterol and phospholipids than for bile acids. As a result, the molar percentages of these biliary constituents changed continuously during these first $22 \mathrm{~h}$ after interruption (Fig. 2).

After 8 days of diversion, bile flow and cholesterol output were at the same levels as observed during the first day after interruption. Bile acid output had, however, increased 2-3-fold after 8 days, whereas biliary phospholipid output showed a $50 \%$ decrease (Fig. 1). The molar percentages of bile acids and phospholipids had returned to approximately the same values as observed immediately after interruption; that of cholesterol, on the other hand, had increased from initially $0.9 \%$ to $1.9 \%$ (Fig. 2 ). The increase in bile acid output after 8 days of biliary drainage was accompanied by only a small increase in bile flow, confirming earlier observations by others [23] and ourselves [5] that long-term biliary drainage leads to a decrease of the bileacid-independent fraction of bile flow.

The relation between biliary bile acid and lipids differed 

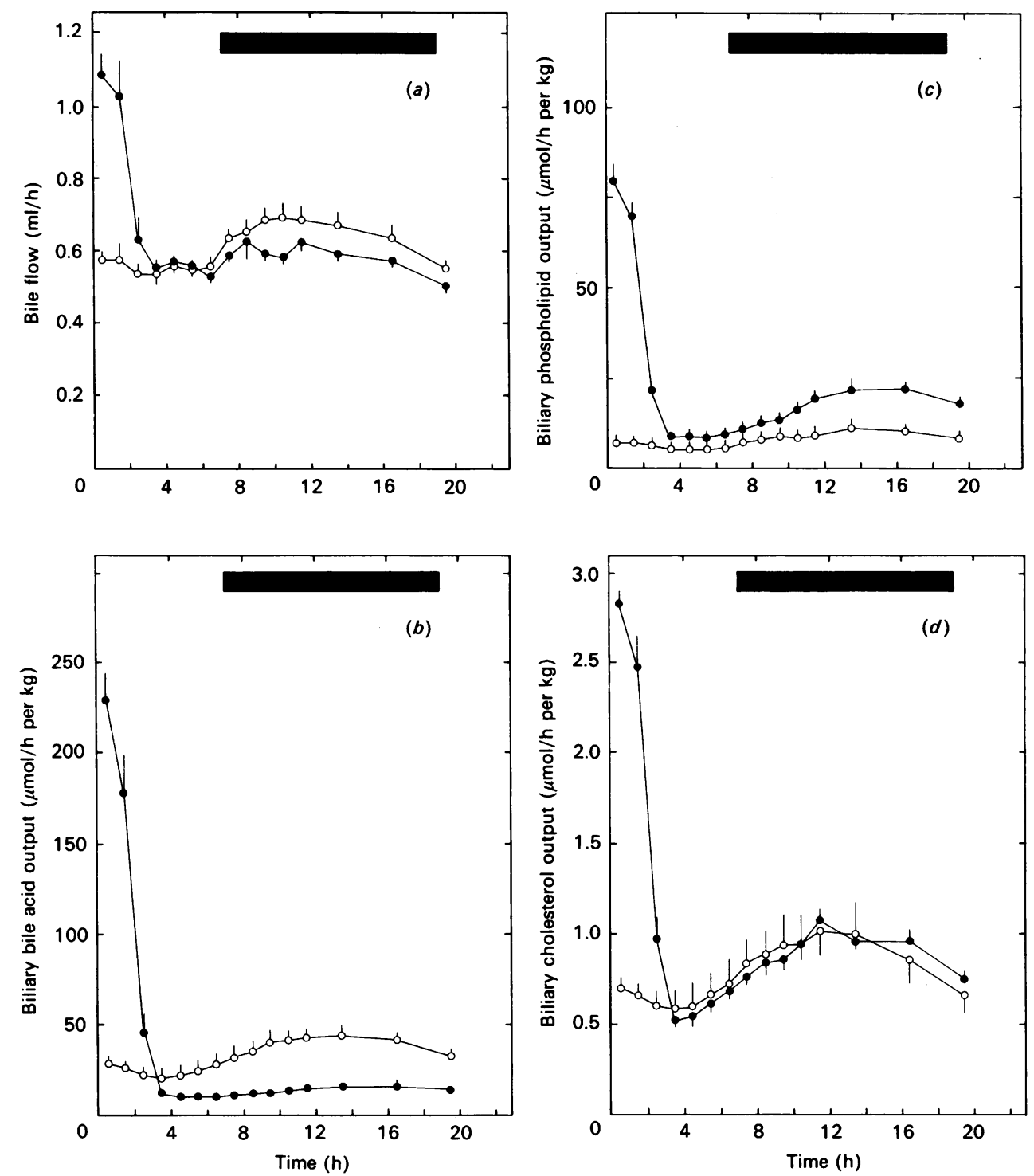

Fig. 1. Bile flow (a), biliary bile acid excretion (b), biliary phospholipid excretion (c) and biliary cholesterol excretion (d), during a period of $22 \mathrm{~h}$ immediately after the beginning of bile diversion $(O)$ and after 8 days of bile diversion $(O)$

Horizontal bars indicate the dark period. Values are means \pm S.E.M. $(n=5)$.

markedly in the two experimental conditions. Fig. 3 shows the ratio of bile acids to cholesterol + phospholipids. This ratio decreased to very low levels $(<1)$ after interruption of the EHC, but had increased to a higher level $(>4)$ after 8 days of bile diversion.

\section{Plasma and liver cholesterol concentrations}

Interruption of the EHC was followed by a $16 \%$ decrease in plasma cholesterol concentration (Table 1) at $22 \mathrm{~h}$ after interruption. After 8 days, plasma cholesterol concentration was still lower than in the control group. This difference was, however, not statistically significant.

The total amount of cholesterol in the liver had decreased by $9 \%$ during the first $22 \mathrm{~h}$ after interruption of the EHC as compared with control values, and remained at this low value during long-term bile diversion. This decrease was mainly due to a fall in the amount of cholesteryl ester, to $58 \%$ of control values. After 8 days, the amount of ester had decreased further, to $42 \%$ of the control value.

\section{Enzyme activities}

The activities of ACAT, HMG-CoA reductase and cholesterol $7 \alpha$-hydroxylase, the rate-limiting enzymes in cholesterol esterification, cholesterol synthesis and bile acid synthesis, respectively, were determined in microsomes obtained from livers of the three groups of rats. As shown in Fig. 4, there was a slight decrease in the activity of ACAT after interruption of the EHC, whereas both HMG-CoA reductase and cholesterol $7 \alpha-$ hydroxylase were already greatly enhanced after $22 \mathrm{~h}$ and had increased further after 8 days.

\section{Hepatic processing of $\left[{ }^{3} \mathrm{H}\right]$ cholesteryl oleate-labelled LDL}

To gain insight into the effects of bile diversion on the hepatic handling of lipoprotein-derived cholesteryl ester, all three experimental groups of rats were intravenously injected with a tracer dose of human LDL labelled with $\left[{ }^{3} \mathrm{H}\right]$ cholesteryl oleate.

No effect of interruption of the EHC on the plasma elimination of $\left[{ }^{3} \mathrm{H}\right]$ cholesteryl oleate-labelled LDL was observed (Fig. 5). 


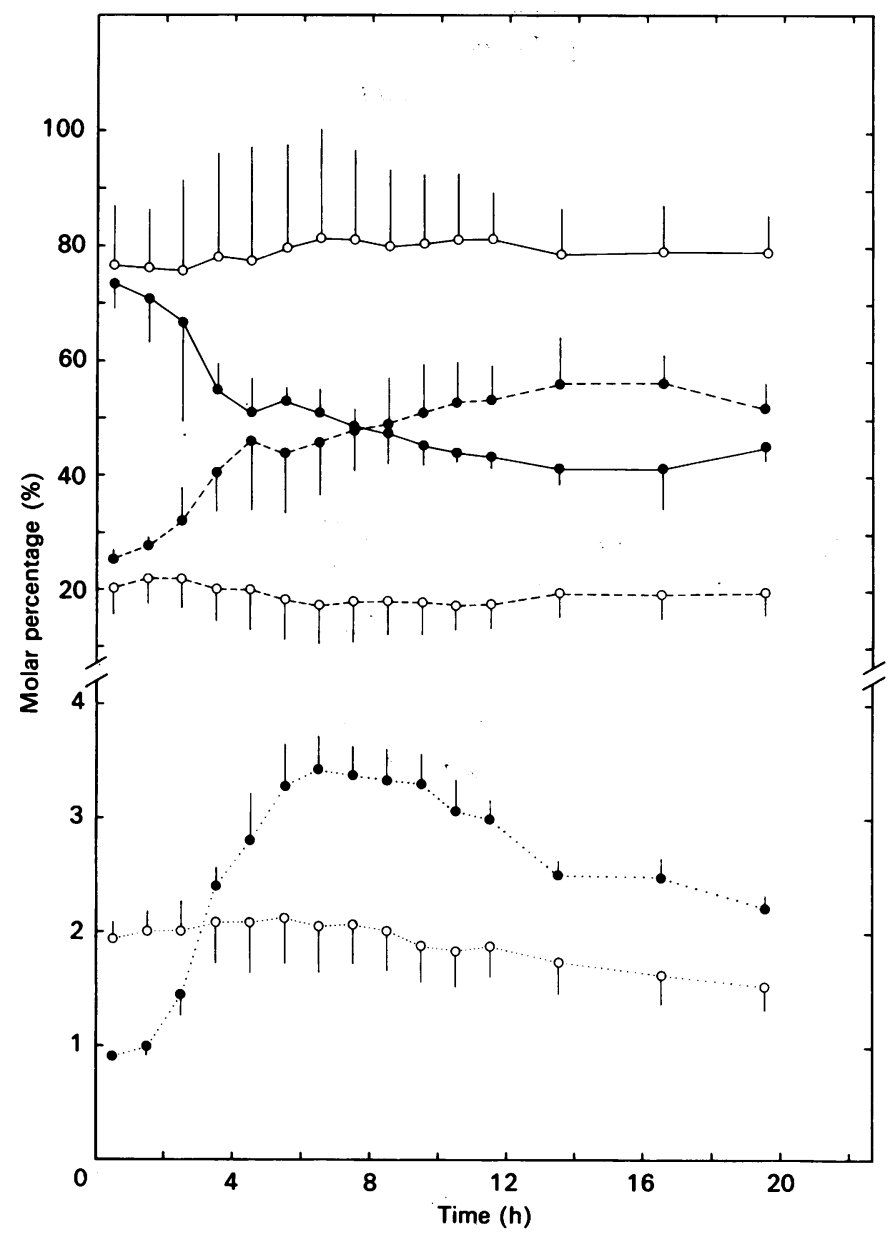

Fig. 2. Molar percentages of bile acids (-), phospholipids (---) and cholesterol $(\cdots \cdots)$ in bile during a period of $22 \mathrm{~h}$ immediately after the beginning of bile diversion $(O)$ and after 8 days of bile diversion $(O)$

Values are means \pm S.E.M. $(n=5)$.

From these results it can be assumed that the amount of labelled lipoprotein taken up by the liver was the same for all three experimental groups.

Biliary excretion of radioactivity occurred most rapidly in chronically interrupted rats. At $4 \mathrm{~h}$ after injection $2.8 \%$ of the dose had been excreted, compared with only $1.0 \%$ of the dose in rats of which the EHC had been interrupted at the time of injection. After $22 \mathrm{~h}$ these values were $16 \%$ and $11 \%$ of the dose respectively. In agreement with this observation, the liver of chronically interrupted rats contained the lowest amount of radioactivity at $22 \mathrm{~h}$ after injection (Table 2 ).

Radioactivity in bile was predominantly present in the form of bile acids $(>90 \%)$. The total biliary excretion of LDL-derived radioactivity in bile acids and the specific radioactivity of the bile acids are shown in Fig. 6. The excretion of radioactivity in the form of bile acids immediately after interruption of the EHC started much more slowly than excretion in chronically interrupted rats, but gradually increased to the same level (Fig. 6a). The low specific radioactivity immediately after interruption (Fig. 6b) largely resulted from the high output of unlabelled bile acids from the pool in this period. After $3 \mathrm{~h}$ the pool of bile acids was exhausted, and biliary bile acid output directly reflected synthesis de novo, which led to an increase in specific radioactivity.

The total amount of radioactivity excreted in the form of cholesterol was only $0.47 \%$ of the dose $/ 22 \mathrm{~h}$ in the chronically

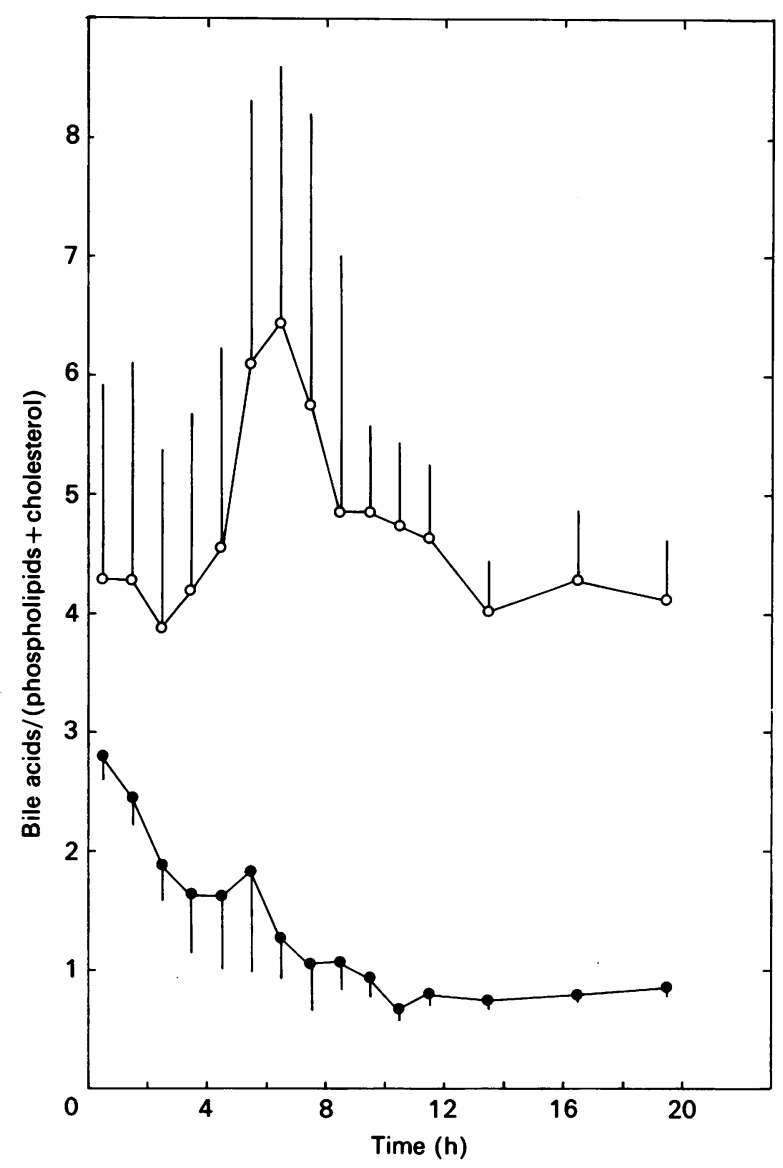

Fig. 3. Biliary bile acid/(phospholipid + cholesterol) molar ratio during a period of $22 \mathrm{~h}$ immediately after the beginning of bile diversion (O) and after 8 days of bile diversion $(O)$

Values are means \pm S.E.M. $(n=5)$.

Table 1. Effect of biliary diversion on plasma and liver cholesterol concentrations

Values are means \pm S.E.M. $(n=5):{ }^{*}$ significantly different from the corresponding value for animals with an intact EHC at $P<0.05$.

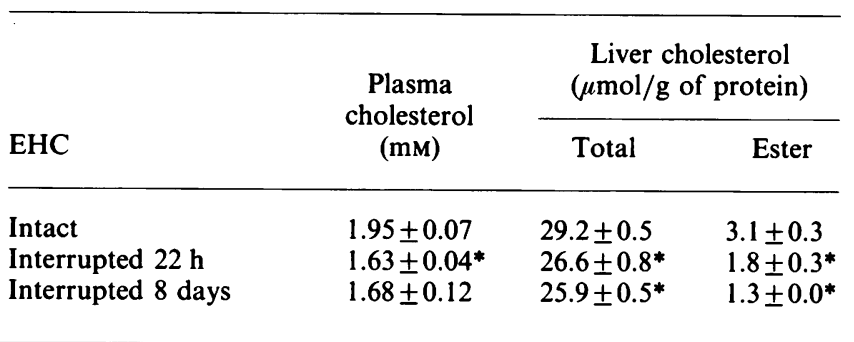

interrupted rats, versus $0.77 \% / 22 \mathrm{~h}$ in the short-term-interrupted rats. Fig. 7 shows the biliary excretion of LDL-derived radioactivity in cholesterol. A peak in excretion of radioactivity in cholesterol was observed immediately after interruption. After the initial peak, the excretion of radioactivity in cholesterol slowly increased, to a level which was higher than excretion in the chronically interrupted rats. Remarkably, excretion of radioactive cholesterol in chronically interrupted rats decreased to a very low level during the last period of the experiment, leading to a very low specific radioactivity of biliary cholesterol. This decrease was much more pronounced than the decrease in radioactivity in bile acids in the same time period. At $22 \mathrm{~h}$ after injection, the specific radioactivity of hepatic cholesterol in 


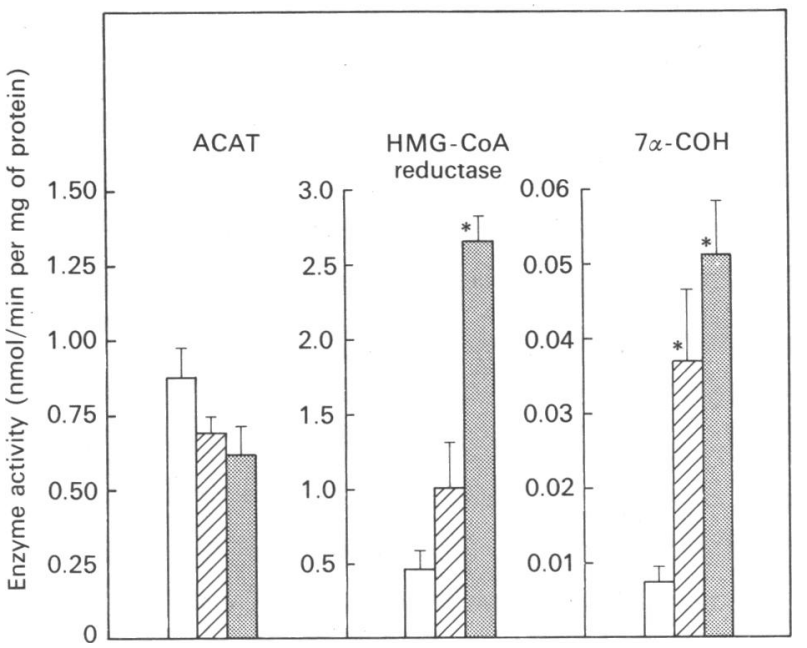

Fig. 4. Microsomal ACAT, HMG-CoA reductase and cholesterol $7 \alpha-$ hydroxylase activity in intact rats $(\square)$, after $22 \mathrm{~h}$ of bile diversion (『) and after 8 days of bile diversion (圆)

Microsomes were prepared from rat livers, and enzyme activities were determined as described in the Materials and methods section. Values are means \pm S.E.M.: $n=3$ for 8 days bile diversion; $n=4$ for intact EHC and $22 \mathrm{~h}$ bile diversion. ${ }^{*}$ Significantly different $(P<0.05)$ from enzyme activity in microsomal preparations from rats with intact EHC. Abbreviation: $7 \alpha-\mathrm{COH}$, cholesterol $7 \alpha-$ hydroxylase.

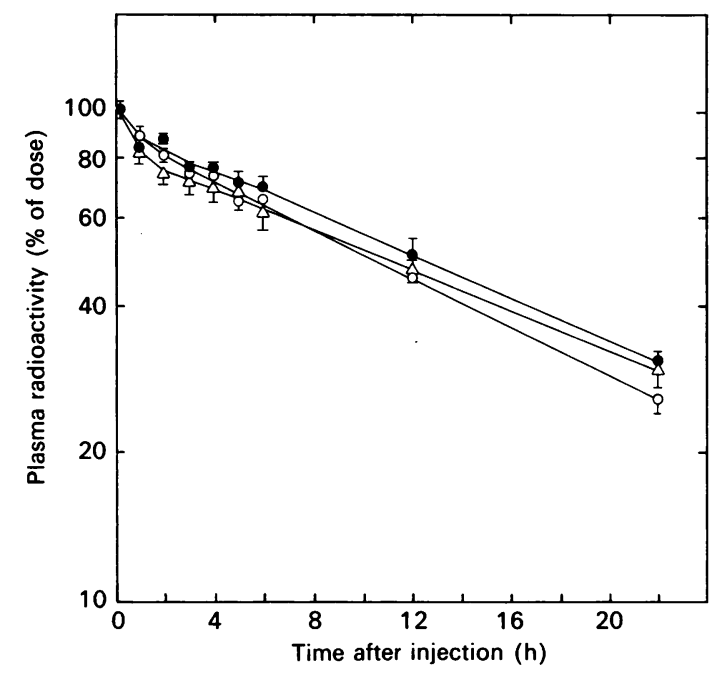

Fig. 5. Plasma elimination of $\left[{ }^{3} \mathrm{H}\right]$ cholesteryl oleate-labelled $L D L$ in rats with chronic and acute biliary drainage and rats with an intact EHC

$\left[{ }^{3} \mathrm{H}\right]$ Cholesteryl oleate-labelled human LDL $\left(8 \times 10^{5}\right.$ d.p.m., $50 \mu \mathrm{g}$ of protein) was introduced intracardially via a permanent heart catheter in rats with 8 days biliary drainage $(O)$, acute biliary drainage $(O)$ and rats with an intact EHC $(\triangle)$. The EHC of the rats with acute biliary drainage was interrupted at the time of injection. At the indicated time points, a $100 \mu$ l blood sample was withdrawn from the heart catheter and radioactivity was determined in plasma. Values are means \pm S.E.M. $(n=5)$.

short-term-interrupted rats was $1374 \pm 82$ d.p.m. $/ \mu$ mol. The specific radioactivities of bile acids and biliary cholesterol at that moment were $1044 \pm 51$ and $1418 \pm 407$ d.p.m. $/ \mu$ mol respectively. In 8-days-diverted rats the specific radioactivity of hepatic cholesterol was $888 \pm 45$ d.p.m. $/ \mu \mathrm{mol}$ at $22 \mathrm{~h}$ after injection, and those of bile acids and biliary cholesterol were $518 \pm 23$ and $207 \pm 136$ d.p.m. $/ \mu \mathrm{mol}$ respectively.
Table 2. Amount of recovered ${ }^{3} \mathrm{H}$ radioactivity in bile and liver

Total amount of recovered ${ }^{3} \mathrm{H}$ radioactivity in bile and liver at $22 \mathrm{~h}$ after injection of $\left[{ }^{3} \mathrm{H}\right]$ cholesteryl oleate-labelled LDL in rats with an intact EHC, rats in which the EHC was interrupted at the time of injection and in rats with a chronically interrupted EHC for 8 days. Values are means \pm S.E.M. $(n=5)$. All values are significantly different from the corresponding values in the same column $(P<0.05)$.

Recovered ${ }^{3} \mathrm{H}$ radioactivity $(\%$ of dose)

\begin{tabular}{lcr}
\cline { 2 - 3 } EHC & Bile & Liver \\
\hline Intact & - & $11.4 \pm 0.3$ \\
Interrupted 22 h & $11.4 \pm 0.4$ & $9.1 \pm 0.4$ \\
Interrupted 8 days & $16.4 \pm 1.0$ & $6.3 \pm 0.3$
\end{tabular}
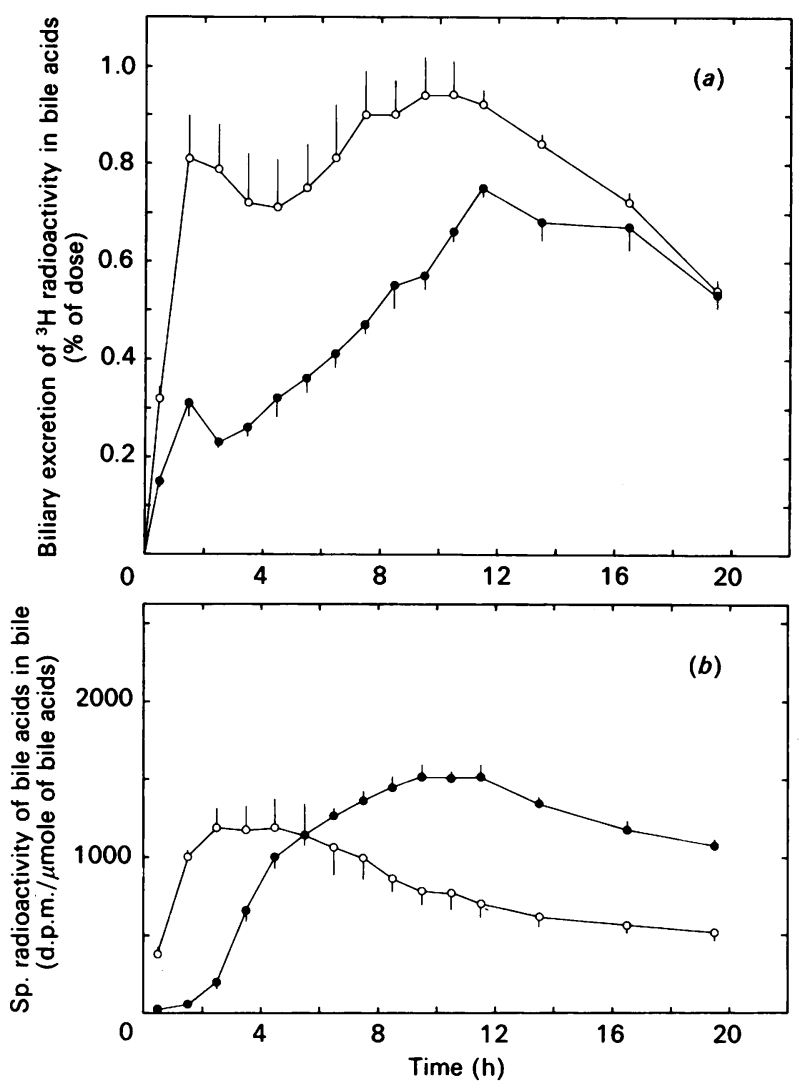

Fig. 6. Biliary excretion of $\left[{ }^{3} \mathrm{H}\right]$ cholesteryl oleate-derived radioactivity in bile acids $(a)$ and specific radioactivity of the bile acids $(b)$

$\left[{ }^{3} \mathrm{H}\right]$ Cholesteryl oleate-labelled human LDL was introduced intracardially via a permanent heart catheter in rats with 8 days biliary drainage via a permanent bile catheter $(O)$ and in rats with an intact EHC via a permanent bile and duodenum catheter that was interrupted at the time of injection (O). Bile was collected for $22 \mathrm{~h}$. Excretion of radioactivity in bile acids $(a)$ is expressed as the mean percentage of the injected dose/h, \pm S.E.M. $(n=5)$. Specific radioactivity of the bile acids $(b)$ is expressed as the mean d.p.m. $/ \mu \mathrm{mol}$ of bile acid, \pm S.E.M. $(n=5)$.

\section{DISCUSSION}

This paper describes the rapid and long-term changes in hepatic cholesterol metabolism and biliary secretion that occur in the rat after interruption of the EHC. The dramatic decrease in bile acid output observed immediately after interruption of the EHC is due to exhaustion of the intestinal pool, a process which 

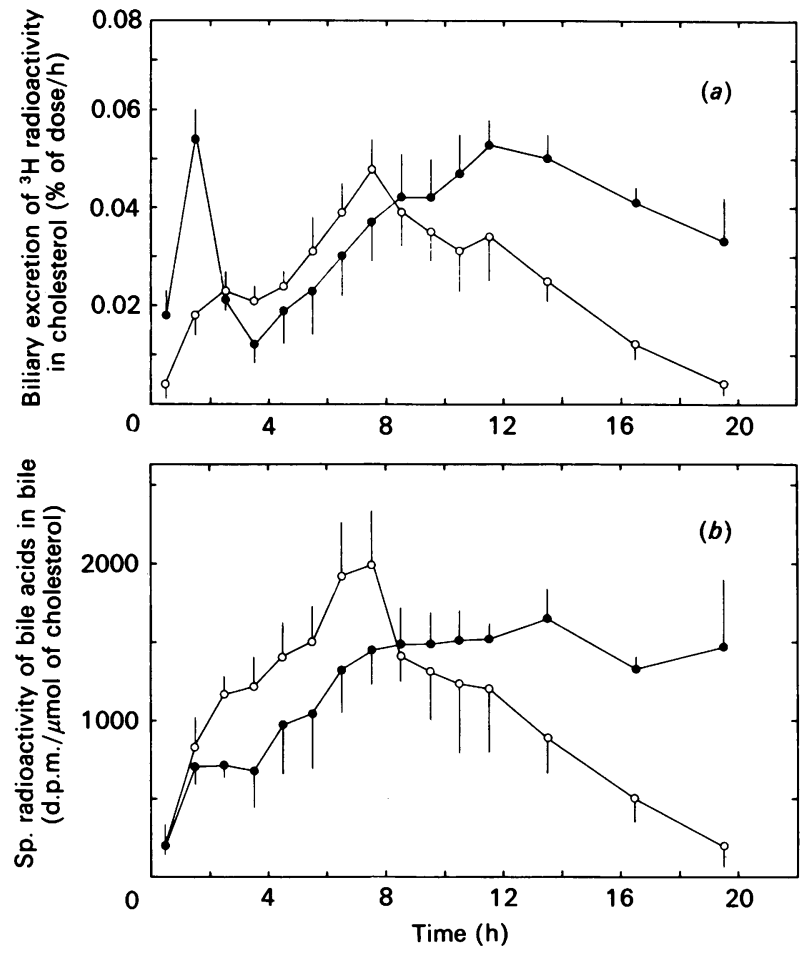

Fig. 7. Biliary excretion of $\left[{ }^{3} \mathrm{H} \mid\right.$ cholesteryl oleate-derived radioactivity in cholesterol $(a)$ and specific radioactivity of biliary cholesterol (b)

Conditions and presentation of the results are the same as in Fig. 6.

takes about $3 \mathrm{~h}$ in unanaesthetized rats, but much longer (i.e. $6 \mathrm{~h}$ or more) in restrained or anaesthetized rats [3,4]. After this depletion period, biliary bile acid output directly reflects hepatic synthesis rate. During long-term interruption, up-regulation of hepatic bile acid synthesis led to a 2-3-fold increase in bile acid output. However, the activity of cholesterol $7 \alpha$-hydroxylase, the rate-limiting enzyme in bile acid synthesis, showed a 7-fold increase. This apparent discrepancy between enzyme activity and bile acid production can be due to a decreased substrate availability, or to a limited capacity of some other enzyme or transport system involved in bile acid synthesis. A shortage of the product of HMG-CoA reductase, mevalonic acid, can be ruled out in our experimental system: we have shown previously that infusion of mevalonic acid in rats with chronic bile diversion is not accompanied by an increase in bile acid synthesis [24]. These results are in agreement with the observations by Einarsson et al. $[25,26]$ that cholesterol $7 \alpha$-hydroxylase is almost fully saturated under basal conditions and that stimulation of enzyme activity does not lead to major changes in saturation of the enzyme. Enzymes catalysing subsequent steps in bile acid synthesis have been shown to be not, or much less, stimulated by bile diversion $[27,28]$. A similar discrepancy between enzyme activity and bile acid production has been observed in isolated rat hepatocytes stimulated with dexamethasone [29]. Other important enzymes in cholesterol homoeostasis also responded to interruption of the EHC. HMG-CoA reductase showed a 6-fold increase, which was accompanied by a small decrease in the amount of free cholesterol in the liver and in plasma. The amount of cholesteryl ester decreased to $58 \%$ at $22 \mathrm{~h}$ after interruption, and further to $42 \%$ of the control value in long-term-diverted rats. ACAT activity was only slightly decreased; a certain amount of ester was maintained, despite the high demand for cholesterol for bile acid synthesis. This amount might be the supply necessary for the assembly of very-low-density lipoprotein particles [30].
Cholesterol and phospholipid secretion into bile decreased after interruption of the EHC, in part because their secretion is coupled to bile acid secretion [31,32]. However, other regulating factors should also be considered, as also suggested by other authors [33,34]. The ratio of bile acids to lipids [bile acids/(phospholipid + cholesterol)] immediately after interruption of the EHC, i.e. a situation comparable with the intact animal, was 2.8. After exhaustion of the pool this value fell to 0.8 , indicating an increase in the amount of lipids as compared with bile acids. A similar dissociation at low bile-acid output rates has been reported previously in rats $[35,36]$ and also in man [37] and rhesus monkey [37]. However, this ratio changed with time; the more than 2-fold increase in bile acid output after 8 days of bile diversion was accompanied by an even further decrease in phospholipid excretion and no change in cholesterol excretion. This resulted in an average bile acid/lipid ratio of 4.6. Therefore, the capacity of a bile acid to induce lipid secretion is determined to a large extent by the experimental conditions. The mechanism responsible for the observed changes in bile acid to lipid ratio remains obscure. Bile formation, bile acid and cholesterol synthesis are heterogeneously distributed in the liver [38]. The flux of bile acids through the liver is concentrated in the periportal area under the conditions of intact EHC [39,40]. Bile acid synthesis is low in this area and high in the perivenous area [41]. After exhaustion of the bile acid pool (3-4 h), the composition of biliary bile acids changes as secondary and tertiary bile acids disappear. Bile acid output at that moment originates mainly from perivenous hepatocytes, which subsequently changes to a more even distribution over all hepatocytes after long-term bile diversion [41]. In contrast, cholesterol synthesis is localized in periportal hepatocytes under control conditions and probably remains in this area after long-term interruption $[38,42]$. So a cascade of changes occurs in composition of biliary bile acids, as well as in location and rate of bile acid synthesis and rate of cholesterol synthesis after interruption of the EHC. All these factors may play a role in determining the bile acid/lipid ratio in bile.

We have used a tracer dose of $\left[{ }^{3} \mathrm{H}\right]$ cholesteryl ester-labelled human LDL as a tool to study changes in hepatic handling of lipoprotein-derived cholesterol. The catabolism of this particle in the rat has been studied extensively [43-47]. About $70-80 \%$ of the human LDL that is removed from the blood is internalized by the liver $[43,45]$. It has been shown that non-parenchymal cells, mainly the Kupffer cells, contribute $71 \%$ of the total liver uptake of this particle in the rat [43]. We have recently studied the biliary secretion of the cholesteryl ester moiety of human LDL and of modified LDL in relation to the site of uptake in the liver in short-term-interrupted rats $[14,48]$. After hydrolysis of the ester, a major part of the labelled cholesterol enters the circulation again and is distributed in the body. As a result, hepatic uptake of LDL is not efficiently coupled to biliary secretion [14,48-51]. The present study shows that plasma elimination of human LDL was not changed after long-term interruption of the EHC, indicating that the putative LDLreceptor activity on non-parenchymal and parenchymal liver cells was not increased. The LDL receptor on Kupffer cells has been shown to have recognition characteristics which differ from those of the classical LDL receptor [46]. Rat hepatocytes exhibit only a low receptor activity towards LDL particles containing solely apoprotein B. So far, only treatment with ethinyloestradiol has resulted in elevated LDL-receptor activity on rat hepatocytes $[14,44,50]$. Our finding that receptor activity was not increased after long-term interruption of the EHC is in agreement with the observations that the rat can alter its rate of hepatic cholesterol synthesis over a very wide range to adapt to changes in supply or faecal loss [51]. 
After exhaustion of the bile acid pool, the mass excretion of cholesterol into bile fell from 2.8 to about $0.5 \mu \mathrm{mol} / \mathrm{h}$ per $\mathrm{kg}$. Assuming that the sources of biliary cholesterol (i.e. lipoprotein cholesterol or biosynthetic cholesterol) do not change considerably during the first period after EHC interruption, it is likely that in intact rats the excretion of radioactive lipoproteinderived cholesterol is about 5 times that observed in our experiments. As Fig. 7 shows, a peak in excretion of radioactive cholesterol was observed during the first $3 \mathrm{~h}$ after interruption of the EHC. This phenomenon is probably due to the high excretion of bile acids into the bile during this period, resulting in a rapid excretion of lipoprotein-derived cholesterol. Despite a similar hepatic uptake of lipoprotein, excretion of radioactive bile acids occurred much faster in chronically interrupted rats than in short-term-interrupted rats (Figs. 6 and 7). This can be related to the higher bile-acid-synthesis rate in the first group, but additionally also to a smaller metabolic pool of cholesterol from which bile acids are synthesized and/or a faster rate of turnover of this pool in these animals.

The specific radioactivity of total hepatic cholesterol at $22 \mathrm{~h}$ after injection in short-term-interrupted rats was higher than the specific radioactivity of the bile acids, but that of biliary cholesterol was not significantly different from that of bile acids and hepatic cholesterol. From our previous work we know that at that time about $75 \%$ of the label in the liver is present in parenchymal cells [14]. As the labelled cholesterol is not preferentially used for biliary excretion, these results suggest that in these rats the lipoprotein-derived cholesterol enters a metabolic pool, which is in equilibrium with the total pool of cholesterol. Robins et al. [52] recently showed similar results using $\left[{ }^{3} \mathrm{H}\right]$ cholesteryl-ester-labelled high-density-lipoprotein recombinants. In contrast with these findings is the observation that in long-term-interrupted rats specific radioactivity of biliary cholesterol declined to a very low level at $22 \mathrm{~h}$ after injection. At the same time, the specific radioactivity of the bile acids was still at an appreciable level, indicating that somehow part of the labelled lipoprotein-derived cholesterol present in the liver was not used for direct biliary excretion, although it was available for bile acid synthesis. These results show that under certain circumstances compartmentalization of hepatic cholesterol occurs.

In conclusion, the results presented in this paper substantiate the important regulatory role of the EHC in cholesterol metabolism. They delineate the necessity of carefully controlled conditions for experimental studies on this subject.

This study was supported by grant $86-067$ from the Dutch Heart Foundation. Part of this work was presented at the Aspen Hepatic Cholesterol and Lipoprotein Conference 1989. F. K. is a Research Fellow of the Royal Netherlands Academy of Arts and Sciences. We thank Albert Gerding for analytical support, and Lodewijk Martijn for drawing the Figures.

\section{REFERENCES}

1. Dietschy, J. M. (1984) Klin. Wochenschr. 62, 338-345

2. Packard, C. J. \& Shepherd, J. (1982) J. Lipid Res. 23, 1081-1099

3. Eriksson, S. (1952) Proc. Soc. Exp. Biol. Med. 94, 578-583

4. Turley, S. D. \& Dietschy, J. M. (1981) J. Biol. Chem. 256, 2438-2446

5. Kuipers, F., Dijkstra, T., Havinga, R., Van Asselt, W. \& Vonk, R. J. (1985) Biochem. Pharmacol. 34, 1731-1736

6. Goodman, L. S. \& Gilman, A. (1980) in The Pharmacological Basis of Therapeutics, 6th edn. (Goodman, L. S. \& Gilman, A., eds.), pp. 349-361, MacMillan, New York

7. Ruckebusch, Y. (1981) Adv. Vet. Sci. Comp. Med. 25, 345-369

8. Weis, E. E. \& Barth, C. A. (1978) J. Lipid Res. 19, 856-862

9. Redinger, R. N., Hawkins, J. W. \& Grace, D. M. (1984) J. Lipid Res. 25, 428-436
10. Kuipers, F., Havinga, R., Bosschieter, H., Toorop, G. P., Hindriks, F. R. \& Vonk, R. J. (1985) Gastroenterology 88, 403-411

11. Steffens, A. B. (1969) Physiol. Behav. 4, 833-836

12. Redgrave, T. G., Roberts, D. C. K. \& West, C. E. (1975) Anal. Biochem. 65, 42-49

13. Blomhoff, R., Drevon, C. A., Eskild, W., Helgerud, P., Norum, K. R. \& Berg, T. (1984) J. Biol. Chem. 259, 8898-8903

14. Nagelkerke, J. F., Bakkeren, H., Kuipers, F., Vonk, R. J. \& van Berkel, Th. J. C. (1986) J. Biol. Chem. 261, 8908-8913

15. Billheimer, J. T., Tavani, D. \& Nes, W. R. (1981) Anal. Biochem. 111, 331-335

16. Princen, H. M. G., Huijsmans, C. M. G., Kuipers, F., Vonk, R. J. \& Kempen, H. J. M. (1986) J. Clin. Invest. 78, 1064-1071

17. Princen, H. M. G., Meijer, P., Kwekkeboom, J. \& Kempen, H. J. M. (1988) Anal. Biochem. 171, 158-165

18. Philipp, B. W. \& Shapiro, D. J. (1979) J. Lipid Res. 20, 588-593

19. Bligh, E. G. \& Dyer, W. J. (1959) Can. J. Biochem. Biophys. 37, 911-917

20. Gamble, W., Vaughan, M., Kruth, M. S. \& Avigan, J. (1978) J. Lipid Res. 19, 1068-1071

21. Böttcher, C. F. J., van Gent, C. M. \& Pries, C. (1961) Anal. Chim. Acta 24, 203-204

22. Lowry, O. H., Rosebrough, N. J., Farr, A. L. \& Randall, R. J. (1951) J. Biol. Chem. 193, 265-275

23. Balabaud, C., Kron, K. A. \& Gumucio, J. J. (1977) J. Lab. Clin Med. 89, 393-399

24. Kempen, H. J. M., de Lange, J., Vos-Van Holstein, M. P. M., van Wachem, P., Havinga, R. \& Vonk, R. J. (1984) Biochem. Biophys. Acta 794, 435-443

25. Einarsson, K., Reihnér, E. \& Björkhem, I. (1989) J. Lipid Res. 30, 1477-1481

26. Einarsson, K., Akerlund, J.-E. \& Björkhem, I. (1987) J. Lipid Res. 28, 253-256

27. Danielsson, H., Einarsson, K. \& Johansson, G. (1967) Eur. J. Biochem. 2, 44-49

28. Johansson, G. (1970) Eur. J. Biochem. 17, 292-295

29. Princen, H. M. G., Meijer, P. \& Hofstee, B. (1989) Biochem. J. 262, 341-348

30. Guo, L. S. S., Hamilton, R. L., Ostwold, R. \& Havel, R. J. (1982) J. Lipid Res. 23, 543-555

31. Hardison, W. G. M. \& Apter, J. T. (1972) Am. J. Physiol. 222, 61-67

32. Wheeler, H. O. \& King, K. K. (1972) J. Clin. Invest. 51, 1337-1350

33. Tavoloni, N. (1986) Biochim. Biophys. Acta 879, 186-201

34. Nervi, F., Bronfman, M., Allalon, W., Depiereux, E. \& Del Pozo, R (1984) J. Clin. Invest. 74, 2226-2237

35. Rahman, K. \& Coleman, R. (1986) Biochem. J. 237, 301-304

36. Rahman, K., Hammond, T. G., Clark, B., Lowe, P. J., Barnwell, S. G. \& Coleman, R. (1986) Biochem. J. 234, 421-428

37. Small, D. M. (1968) New Engl. J. Med. 279, 588-593

38. Singer, I. I., Kowka, D. W., Kozanis, D. M., Alberts, A. W., Chen, J. S., Huff, J. W. \& Ness, G. C. (1984) Proc. Natl. Acad. Sci. U.S.A. 81, 5556-5560

39. Jones, A. L., Hradek, G. T., Renston, R. H., Wong, K. Y., Karlogonis, G. \& Paumgartner, G. (1980) Am. J. Physiol. 238, G233-G237

40. Groothuis, G. M. M., Hardonk, M. J., Keulemans, K. P. T., Nieuwenhuis, P. \& Meijer, D. K. F. (1982) Am. J. Physiol. 234, G455-G462

41. Ugele, B., Kempen, H. J. M., Gebhardt, R., Meijer, P., Burger, H.J. \& Princen, H. M. G. (1989) in Trends in Bile Acid Research (Paumgartner, G., Stiehl, A. \& Gerok, W., eds.), pp. 53-61, Kluwer Academic Publishers, Lancaster

42. Li, A. C., Tanaka, R. D., Callaway, K., Fogelman, A. M. \& Edwards, P. A. (1988) J. Lipid Res. 29, 781-796

43. Harkes, L. \& Van Berkel, Th. J. C. (1984) Biochem. J. 224, 21-27

44. Chao, Y., Windler, E. E., Chen, G. C. \& Havel, R. J. (1979) J. Biol. Chem. 254, 11360-11366

45. Pittman, R. C., Attie, A. D., Carew, T. E. \& Steinberg, D. (1982) Biochim. Biophys. Acta 710, 7-14

46. Nagelkerke, J. F., Havekes, L., Van Hinsbergh, V. W. M. \& Van Berkel, Th. J. C. (1984) FEBS Lett. 171, 63-67

47. Harkes, L. \& Van Berkel, Th. J. C. (1984) Biochim. Biophys. Acta 794, 340-347

48. Kuipers, F., Nagelkerke, J. F., Bakkeren, H., Havinga, R., van Berkel, Th. J. C. \& Vonk, R. J. (1989) Biochem. J. 257, 699-704 
49. Bhattacharya, S., Balasubramaniam, S. \& Simons, L. A. (1986) Biochim. Biophys. Acta 876, 413-416.

50. Kovanen, P. T., Brown, M. S. \& Goldstein, J. L. (1979) J. Biol. Chem. 254, 11367-11373

Received 31 January 1990/18 April 1990; accepted 27 April 1990
51. Spady, D. K., Turley, S. D. \& Dietschy, J. M. (1985) J. Lipid Res. 26, 465-472

52. Robins, S. J., Fasulo, J. M., Leduc, R. \& Patton, G. M. (1989) Biochim. Biophys. Acta 1004, 327-331 